\title{
Poliarteritis nodosa cutánea: presentación de dos casos y revisión de literatura
}

\author{
Cutaneous polyarteritis nodosa: \\ presentation of two cases and literature review
}

\author{
Miguel Ángel Hernández-Cardona, ${ }^{\star}$ José Alberto Ramos-Garibay, ${ }^{\ddagger}$ Karla Leticia Valdés-Morales ${ }^{\S}$
}

\section{RESUMEN}

La poliarteritis nodosa cutánea es una vasculitis que afecta sobre todo vasos de mediano y pequeño calibre, cuya incidencia exacta se desconoce por su baja frecuencia. Su etiopatogenia es aún desconocida. Se caracteriza clínicamente por la presencia de nódulos subcutáneos dolorosos asociados a livedo reticularis, que se complican con úlceras que se ubican por lo general en extremidades inferiores. Su curso es crónico, con remisiones y exacerbaciones. Por lo general, afecta únicamente a la piel, aunque en algunos casos se ha observado afección extracutánea. En este artículo, se describen sus diferentes presentaciones y el tratamiento de esta patología en dos pacientes de distinto género y edad.

Palabras clave: Poliarteritis nodosa cutánea, úlceras, nódulos subcutáneos, livedo reticularis.

\section{ABSTRACT}

Cutaneous polyarteritis nodosa is a form of vasculitis that affects small to medium sized arteries, with unknown incidence due to a low frequency. The exact etiopathogenesis is unknown. Clinically, it is characterized by painful subcutaneous nodules associated to livedo reticularis, that frequently evolves to ulcers on lower extremities, with a chronic and relapsing clinical course. Generally, it only involves skin, however, extracutaneous manifestation has been reported. In this article we describe different clinical presentation and management of two patients with different gender and age.

Keywords: Cutaneous polyarteritis nodosa, ulcers, subcutaneous nodules, livedo reticularis.

\section{INTRODUCCIÓN}

La poliarteritis nodosa cutánea (PANC) es una vasculitis cutánea de vasos de mediano calibre, poco común y mediada por complejos inmunes. ${ }^{1}$ Se desconoce su incidencia exacta, aunque se ha descrito que representa $10 \%$ de los casos de poliarteritis sistémica, entidad en la cual, además de la piel, existe vasculitis en riñón, hígado y otros órganos. ${ }^{2}$ Es importante distinguir entre estas dos patologías por las diferencias que existen en su curso clínico y pronóstico. ${ }^{3}$

La PANC se define, según la nomenclatura del consenso de Chapel Hill, como una arteritis cutánea

\footnotetext{
* Dermatooncólogo adscrito de la consulta externa.

₹ Dermatopatólogo.

$\S$ Residente de tercer año de Dermatología.
}

Centro Dermatológico «Dr. Ladislao de la Pascua», SSCDMX. que afecta arterias de mediano calibre en el panículo adiposo, y que puede extenderse a arteriolas en la unión dermoepidérmica, pero sin afectar a las vénulas postcapilares. ${ }^{4}$

Se manifiesta a cualquier edad; sin embargo, prevalece en adultos entre la cuarta y sexta décadas de la vida.

La fisiopatogenia exacta de la PANC aún se desconoce, aunque se considera una enfermedad por depósito de complejos autoinmunes, ya que se han detectado anticuerpos IgM y C3 en la pared de vasos afectados. Se ha demostrado la presencia de anticuerpos IgM contra el complejo de protrombina-fosfatidilserina en pacientes con lesiones activas de PANC, por lo que se ha propuesto que estos anticuerpos juegan un papel importante en

Citar como: Hernández-Cardona MÁ, Ramos-Garibay JA, Valdés-Morales KL. Poliarteritis nodosa cutánea: presentación de dos casos y revisión de literatura. Rev Cent Dermatol Pascua. 2021; 30 (2): 84-88. https://dx.doi.org/10.35366/101178 
la patogenia de esta enfermedad. La protrombina se une a la fosfatidilserina de células endoteliales apoptóticas, creando el complejo protrombina-fosfatidilserina, después anticuerpos IgM se unen a este complejo, lo que lleva a la activación del complemento y al subsecuente desarrollo de una cascada inflamatoria. ${ }^{5}$

Se han descrito múltiples factores desencadenantes: la infección por el estreptococo beta-hemolítico del grupo A es la más común, aunque también se han detectado casos de PANC después de la administración de minociclina. De igual forma, se ha observado una fuerte asociación entre la PAN sistémica y la infección por el virus de la hepatitis $B$, pero lo anterior no se ha corroborado en la PANC. ${ }^{6,7}$

Las manifestaciones cutáneas más frecuentes en esta variedad de vasculitis son la presencia de nódulos subcutáneos, livedo reticularis y posteriormente úlceras. Los nódulos subcutáneos se presentan en $80 \%$ de los casos, por lo general son dolorosos y se acompañan de eritema y edema, en $50 \%$ de los casos, éstos se ulceran. La livedo reticularis se desarrolla en 50 a $80 \%$ de los casos y puede ser el primer dato clínico de esta patología. ${ }^{8}$ La afección en la PANC, como su nombre lo indica, es principalmente cutánea; sin embargo, en algunos casos también se presentan síntomas generales como artralgias, mialgias y neuropatías. ${ }^{9}$

El diagnóstico de PANC se realiza con base en el cuadro clínico, hallazgos histopatológicos y por exclusión de otras vasculitis. En la histopatología destaca la presencia de vasculitis leucocitoclástica, en especial en los vasos de la dermis papilar. ${ }^{10}$ Como parte del abordaje diagnóstico, se debe solicitar también la determinación de anticuerpos anticitoplasma de neutrófilos, anticuerpos antinucleares, factor reumatoide, crioglobulinas y marcadores de inflamación (velocidad de sedimentación globular y proteína $C$ reactiva) para descartar otras vasculitis; en general, en la PANC dichos exámenes de laboratorio se encontrarán negativos, aunque se ha reportado elevación de los marcadores de la inflamación en algunos pacientes..$^{10,11}$

El tratamiento de la PANC depende de la severidad del cuadro clínico. En casos leves, se puede optar por manejo conservador, a base de antiinflamatorios no esteroideos o colchicina para control del dolor, así como la aplicación de esteroides tópicos de alta potencia. ${ }^{3}$ En casos más severos, que no responden al manejo antes descrito, el tratamiento de primera línea consiste en la administración de corticoesteroides sistémicos a dosis antiinflamatorias. Se han utilizado diversos medicamentos en conjunto con estos últimos para optimizar el control del cuadro tales como: azatioprina, dapsona, cloroquina, entre otros; no obstante, faltan ensayos clínicos que confirmen su eficacia. ${ }^{12}$

El curso de la enfermedad cutánea, a diferencia de la variedad sistémica, es crónico con remisiones y recurrencias, lo que altera de forma significativa la calidad de vida del paciente. En un estudio retrospectivo publicado por Kato y colaboradores en el año 2018, los autores detectaron que la presencia de úlceras previamente tratadas, elevación de proteína $\mathrm{C}$ reactiva, cuenta absoluta elevada de neutrófilos, y la relación incrementada de neutrófilos/linfocitos eran factores de mal pronóstico para el desarrollo de recurrencia en la PANC. ${ }^{13}$

De manera excepcional, se ha descrito evolución de PAN cutánea a sistémica, lo anterior se observó en una publicación de una serie de 20 casos, en donde sólo dos de ellos presentaron esta evolución. ${ }^{14}$ En otra serie de casos publicada $(n=79)$, ningún paciente con PANC evolucionó a poliarteritis nodosa clásica..$^{15}$ La PANC es considerada una variante clínica de la poliarteritis nodosa sistémica, aunque se encuentra aún en discusión si es conveniente separar estas dos entidades, ya que su etiopatogenia y evolución clínica son diferentes. ${ }^{15,16}$ Por lo antes señalado, es importante descartar afección extracutánea de forma inicial en todos los pacientes y durante las recurrencias.

\section{CASO 1}

Varón de 12 años de edad, sin antecedentes personales de importancia para su padecimiento actual. Presenta dermatosis diseminada a extremidades inferiores que afecta piernas en sus caras posteriores y laterales, bilateral y con tendencia a la simetría. Constituida por numerosas escaras de forma y tamaño variable, con eritema y escama fina en la periferia de algunas de ellas, así como algunas úlceras (Figuras 1 y 2). Refería un mes de evolución, tratado previamente con múltiples ciclos de antibióticos, esteroides tópicos y antihistamínicos, sin mejoría. Se solicitaron estudios de laboratorio en los que destaca proteinuria de $30 \mathrm{mg} / \mathrm{dL}$ en el examen general de orina, $\mathrm{p}$-ANCA y anticuerpos anticardiolipina negativos. Se realizó biopsia incisional en donde los cortes mostraron epidermis acantósica con zona central ulcerada. Dermis superficial y hasta los lóbulos de la hipodermis con infiltrados moderadamente densos de linfocitos y neutrófilos que rodean a los vasos, que exhiben degeneración fibrinoide en sus paredes, extravasación de eritrocitos y leucocitoclasia. Con estos datos, se realizó el diagnóstico histopatológico de vasculitis leucocitoclástica, haciendo correlación clínica con los resultados de los exámenes de laboratorio y los hallazgos histopatológicos ya descritos, se concluye que se trata 


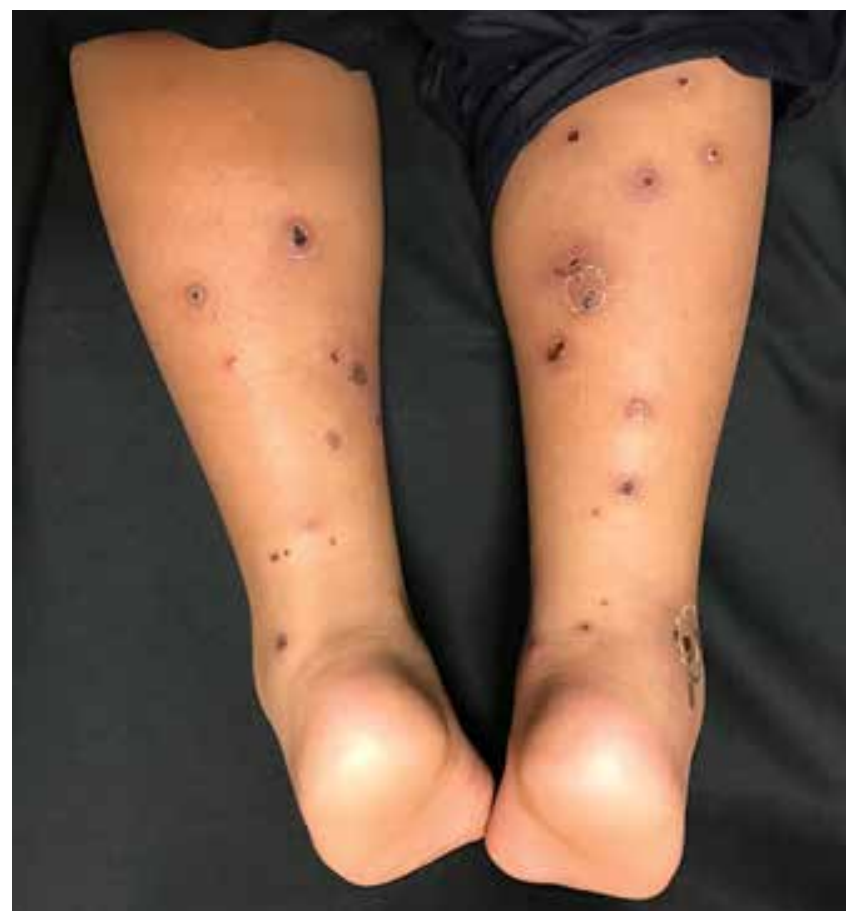

Figura 1: Caso clínico 1. Múltiples nódulos ulcerados, con escaras y escama en la periferia en extremidades inferiores.

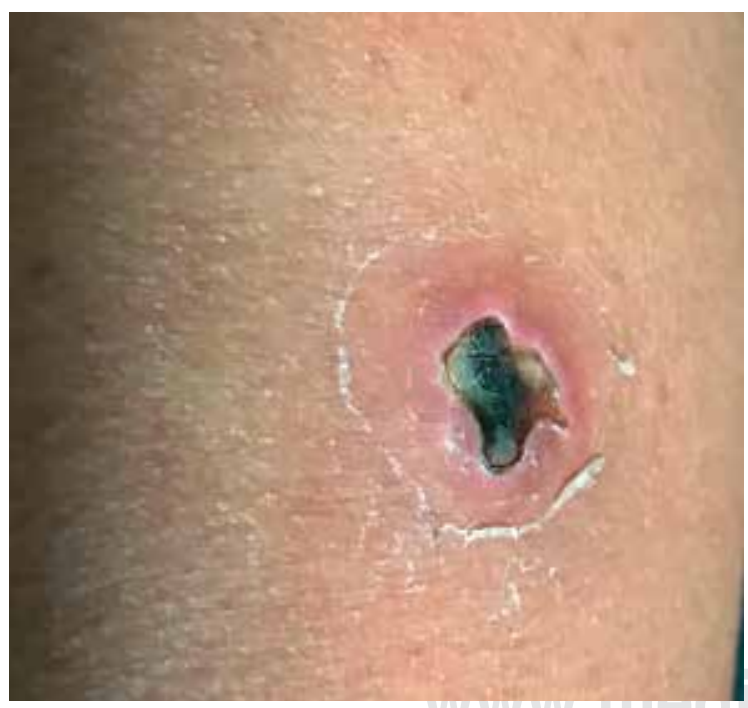

Figura 2: Caso clínico 1. Acercamiento de una de las lesiones.

de una PANC con proteinuria incipiente. El paciente se mantuvo con medidas generales, aplicación de esteroide de alta potencia tópico durante tres meses y crema emoliente con reparador tisular, con lo que las lesiones involucionaron. A los cinco meses de la primera consul- ta, presentaba únicamente cicatrices atróficas en áreas afectadas; en controles posteriores, la proteinuria remitió en su totalidad. Se mantuvo en tratamiento conservador sin presentar nuevas lesiones durante los siguientes siete meses; sin embargo, al octavo mes presentó recurrencia del cuadro con la presencia de nódulos dolorosos que remitieron al reaplicar el mismo tratamiento. Asintomático después de seis meses de su última consulta.

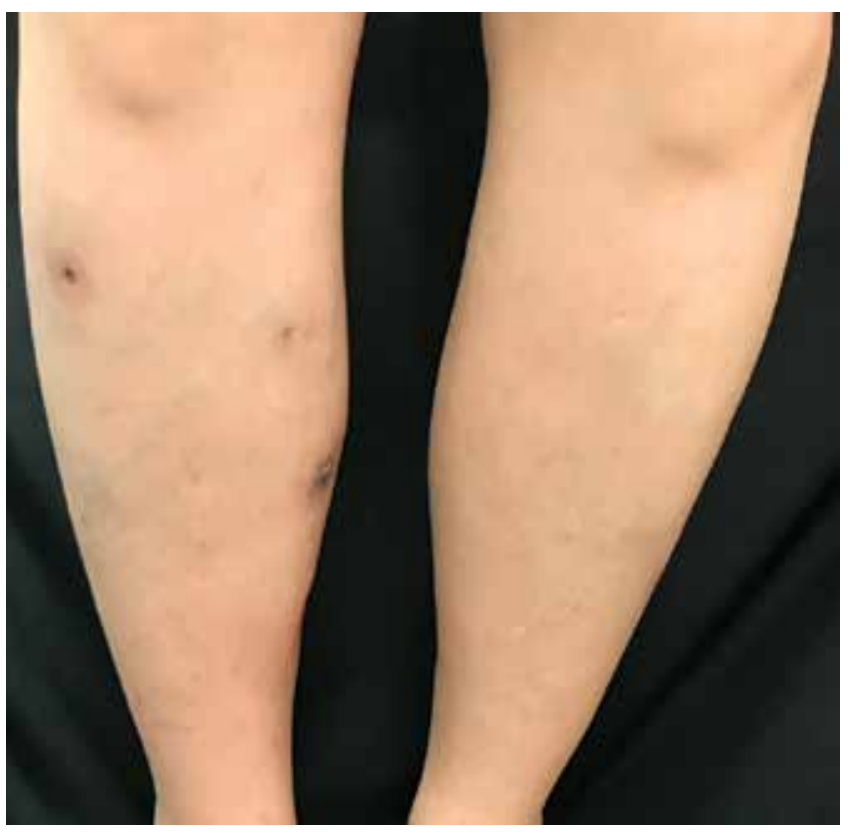

Figura 3: Caso clínico 2. Nódulos eritemato-violáceos con fondo necrótico.

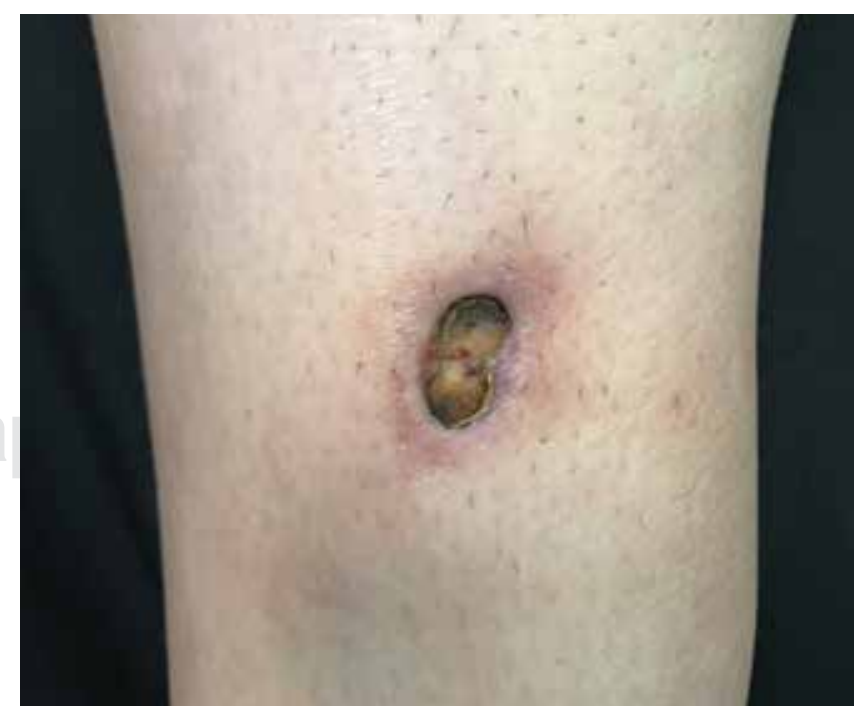

Figura 4: Caso clínico 2. Nódulo ulcerado. 


\section{CASO 2}

Mujer de 45 años de edad, alérgica a la penicilina, naproxeno y sulfas, sin comorbilidades. Presenta dermatosis diseminada a extremidades inferiores de la que afecta piernas en cara anterior y lateral externa, bilateral y asimétrica. Constituida por tres escaras de forma variable, de diversos tamaños, la mayor de $4 \times$ $3 \mathrm{~cm}$, con fondo necrótico, borde de aspecto infiltrado, activo (Figuras 3 y 4). Refiere un mes de evolución. Su presentación inicial coincide con infección de vías aéreas superiores, acompañada de cefalea y fiebre. Se solicitaron exámenes de laboratorio, entre ellos anticuerpos p-ANCA y c-ANCA, velocidad de sedimentación globular, antiestreptolisinas, anti-VHB, prueba rápida de VIH, VDRL y crioglobulinas, los cuales resultaron negativos. Exudado faríngeo positivo para estreptococo betahemolítico del grupo A. Se realizó biopsia incisional, en donde se observa epidermis con capa córnea laminar y tapones córneos con aplanamiento de los procesos interpapilares. En el espesor de la dermis y porción septal del tejido celular subcutáneo se observan vasos que presentan degeneración fibrinoide, los cuales están rodeados e invadidos por neutrófilos y linfocitos; algunos trombosados (Figuras 5 a 8). Se concluye que se trata de vasculitis leucocitoclástica, secundaria a una PANC desencadenada por estreptococo. Se inició tratamiento con antibiótico sistémico y prednisona a dosis de 0.5 $\mathrm{mg} / \mathrm{kg}$ con reducción semanal; sin embargo, tras dos meses de tratamiento, hubo reactivación de las úlceras. Se agregó ahorrador de esteroide (azatioprina) 100 $\mathrm{mg}$ al día, continuando con el tratamiento tópico con emoliente, fomentos con sulfato de cobre, y cicatrizante de heridas, con lo cual hubo remisión del cuadro a los

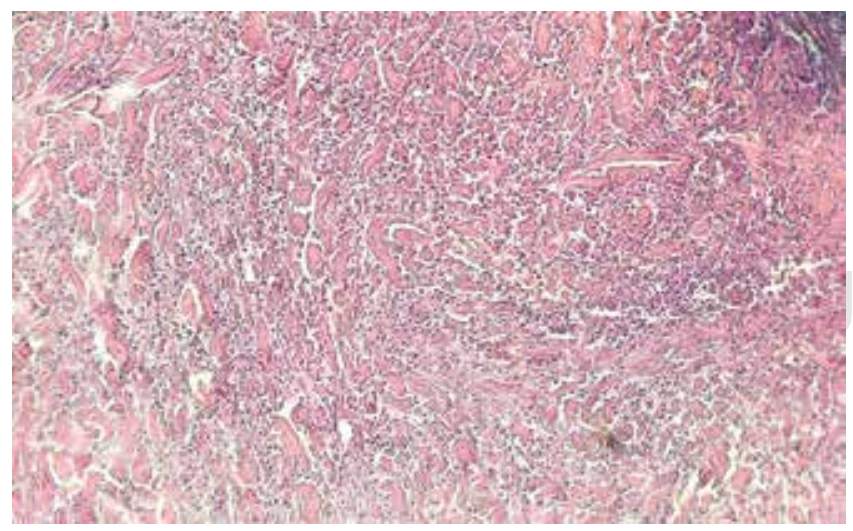

Figura 5: Se observa degeneración de la colágena, así como denso infiltrado (H\&E 10x).
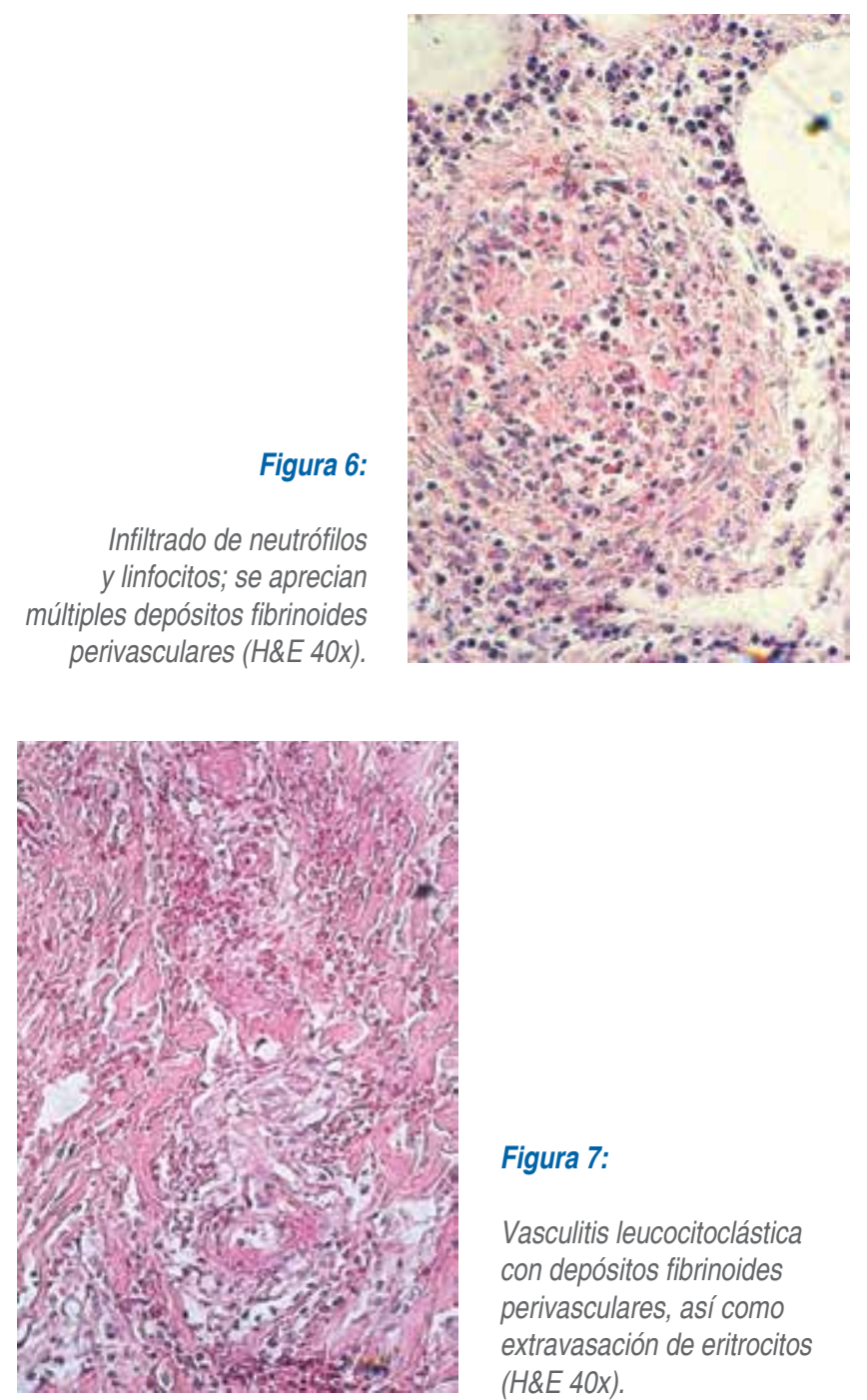

Figura 7:

Vasculitis leucocitoclástica con depósitos fibrinoides perivasculares, así como extravasación de eritrocitos (H\&E 40X).
Figura 8:

Vasculitis leucocitoclástica (H\&E 40x).

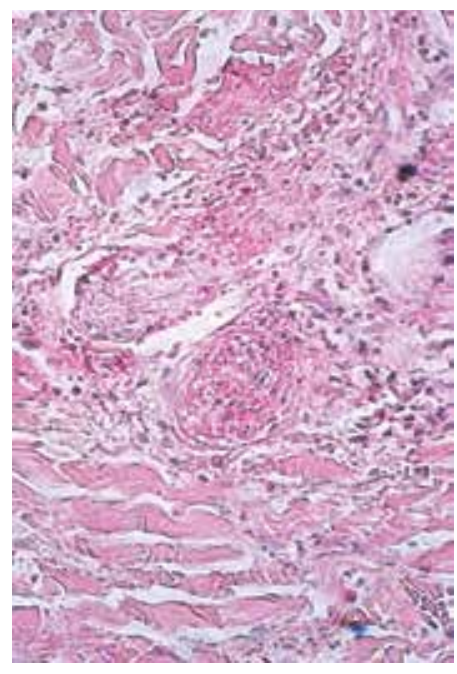


tres meses. A cuatro meses de seguimiento, sólo se observan cicatrices atróficas blanquecinas residuales.

\section{CONCLUSIÓN}

Esta vasculitis debe sospecharse en pacientes que presentan nódulos subcutáneos dolorosos que evolucionan a úlceras que predominan en extremidades inferiores. La realización de un estudio histopatológico, así como solicitar los exámenes de laboratorio específicos e interrogar minuciosamente para tratar de detectar síntomas sistémicos especiales son aspectos esenciales para realizar diagnóstico diferencial con otras enfermedades autoinmunes. En los casos presentados en este artículo, llama la atención el hallazgo de proteinuria en el paciente pediátrico del primer caso, y el antecedente de infección por estreptococo en el segundo caso. Ambos evolucionaron en forma tórpida, con exacerbación y remisión del cuadro, pero con adecuada respuesta al tratamiento, sin progresión hacia la forma sistémica. No se encontraron factores de mal pronóstico para recurrencia.

\section{REFERENCIAS}

1. Parperis K, Rast F. Inner peace: cutaneous polyarteritis nodosa. Am J Med. 2017; 130: 796-798.

2. Bauzá A, España A, Idoate M. Cutaneous polyarteritis nodosa. Br J Dermatol. 2002; 146: 694-699.

3. De Virgilio A, Greco A, Magliulo G, Gallo A, Ruoppolo G, Conte M et al. Polyarteritis nodosa: a contemporary overview. Autoimmun Rev. 2016; 15: 564-570.

4. Sunderkotter $\mathrm{CH}$, Zelger B, Chen KR, Requena L, Piette W, Carlson JA et al. Nomenclature of cutaneous vasculitis: dermatologic addendum to the 2012 revised international chapel hill consensus conference nomenclature of vasculitides. Arthritis Rheumatol. 2018; 70: 171-184.

5. Kawakami T, Yamazaki M, Mizoguchi M, Soma Y. High titer of antiphosphatidylserine-prothrombin complex antibodies in patients with cutaneous polyarteritis nodosa. Arthritis Rheum. 2007; 57: 1507-1513.
6. Culver B, Itkin A, Pischel K. Case report and review of minocyclineinduced cutaneous polyarteritis nodosa. Arthritis Rheum. 2005; 53 : 468-470.

7. Morgan AJ, Schwartz RA. Cutaneous polyarteritis nodosa: a comprehensive review. Int J Dermatol. 2010; 49: 750-756.

8. Criado PR, Marques GF, Morita TC, de Carvalho JF. Epidemiological, clinical and laboratory profiles of cutaneous polyarteritis nodosa patients: report of 22 cases and literature review. Autoimmun Rev. 2016; 15: 558-563.

9. de Menthon M, Mahr A. Treating polyarteritis nodosa: current state of the art. Clin Exp Rheumatol. 2011; 29: S110-S116.

10. Díaz-Pérez JL, De Lagrán ZM, Díaz-Ramón JL, Winkelmann RK. Cutaneous polyarteritis nodosa. Semin Cutan Med Surg. 2007; 26: 77-86.

11. Subbanna PK, Singh NV, Swaminathan RP. Cutaneous polyarteritis nodosa: a rare isolated cutaneous vasculitis. Indian Dermatol Online J. 2012; 3: 21-24.

12. Furukawa F. Cutaneous polyarteritis nodosa: an update. Ann Vasc Dis. 2012; 5: 282-288.

13. Kato A, Hamada T, Miyake T, Morizane S, Hirai Y, Yamasaki O et al. Clinical and laboratory markers associated with relapse in cutaneous polyarteritis nodosa. JAMA Dermatol. 2018; 154: 922-926.

14. Chen KR. Cutaneous polyarteritis nodosa: a clinical and histopathological study of 20 cases. J Dermatol. 1989; 16: 429-442.

15. Daoud MS, Hutton KP, Gibson LE. Cutaneous periarteritis nodosa: a clinicopathological study of 79 cases. Br J Dermatol. 1997; 136: 706-713.

16. Ozen $\mathrm{S}$. The changing face of polyarteritis nodosa and necrotizing vasculitis. Nat Rev Rheumatol. 2017; 13: 381-386.

Correspondencia:

Dr. Miguel Ángel Cardona-Hernández

Centro Dermatológico

"Dr. Ladislao de la Pascua», SSCDMX.

Dr. Vértiz Núm. 464, esq. Eje 3 Sur,

Col. Buenos Aires, 06780,

Alcaldía Cuauhtémoc, CDMX.

Tel: 55 5538-7033

E-mail: drmiguelcardona08@gmail.com 